\title{
HBP1: a HMG box transcriptional repressor that is targeted by the retinoblastoma family
}

\author{
Sergei G. Tevosian, ${ }^{1,2}$ Heather H. Shih, ${ }^{1}$ Kim G. Mendelson, ${ }^{1,2}$ Kelly-Ann Sheppard, ${ }^{1}$ K. Eric \\ Paulson, ${ }^{1,2}$ and Amy S. Yee ${ }^{1,3}$ \\ ${ }^{1}$ The Department of Biochemistry, Tufts University School of Medicine, Boston, Massachusetts 02111 USA; $^{2}$ The Genetics \\ Laboratory, Jean Mayer USDA Human Nutrition Research Center on Aging at Tufts University, \\ Boston, Massachusetts 02111 USA
}

\begin{abstract}
A prominent feature of cell differentiation is the initiation and maintenance of an irreversible cell cycle arrest with the complex involvement of the retinoblastoma (RB) family (RB, p130, p107). We have isolated the HBP1 transcriptional repressor as a potential target of the RB family in differentiated cells. By homology, HBP1 is a sequence-specific HMG transcription factor, of which LEF-1 is the best-characterized family member. Several features of HBP1 suggest an intriguing role as a transcriptional and cell cycle regulator in differentiated cells. First, inspection of the HBP1 protein sequence revealed two consensus RB interaction motifs (LXCXE and IXCXE). Second, HBP1 interaction was selective for RB and p130, but not p107. HBP1, RB, and p130 levels are all up-regulated with differentiation; in contrast, p107 levels decline. Third, HBP1 can function as a transcriptional repressor of the promoter for $\mathrm{N}-\mathrm{MYC}$, which is a critical cell cycle and developmental gene. Fourth, because the activation of the N-MYC promoter in cycling cells required the E2F transcription factor, we show that E2F-1 and HBP1 represent opposite transcriptional signals that can be integrated within the N-MYC promoter. Fifth, the expression of HBP1 lead to efficient cell cycle arrest. The arrest phenotype was manifested in the presence of optimal proliferation signals, suggesting that HBP1 exerted a dominant regulatory role. Taken together, the results suggest that HBP1 may represent a unique transcriptional repressor with a role in initiation and establishment of cell cycle arrest during differentiation.
\end{abstract}

[Key Words: HBP1; HMG transcription factor; retinoblastma family]

Received June 1996; revised version accepted December 17, 1996.

A critical question in cellular growth control and in mammalian development concerns the coordination of cell cycle progression and exit. The irreversible exit from the cell cycle is an essential feature of cellular differentiation and organogenesis, but the mechanisms underlying its initiation and maintenance are not well understood. In diseases such as cancer, a salient feature is the reentry of quiescent and differentiated cells into the cell cycle. This suggests that the normal mechanisms that maintain the postmitotic state have been overridden. Thus, understanding the fundamental mechanisms of cell cycle arrest and exit should provide insights into both normal developmental and aberrant disease processes.

At the heart of cellular proliferation pathways is the retinoblastoma family of growth suppressors (RB, p107, and p130|, and much previous work has focused on its role in regulating the $G_{1} / S$ transition. Growth suppres-

${ }^{3}$ Corresponding author.

E-MAIL ayee@opal.tufts.edu; FAX (617) 636-6409. sion by RB results through arrest in the $G_{1}$ phase of the cell cycle (for review, see Livingston et al. 1993; Riley et al. 1994). The regulation of cell cycle progression by the $\mathrm{RB}$ family requires a complex series of interactions with transcriptional factors such as E2F and with the cell cycle machinery involving cyclins and cyclin-dependent kinases (CDKs) (see excellent reviews in (Farnham 1996). E2F regulates numerous genes involved in growth control, such as N-MYC (e.g., Mudryj et al. 1990). We and others have demonstrated that $\mathrm{RB}$ is a negative regulator of E2F (Bagchi et al. 1991; Chellapan et al. 1991; Chittenden et al. 1991; Huang et al. 1992), consistent with the role of $\mathrm{RB}$ in growth suppression. During the cell cycle, phosphorylation of RB by cyclins and CDK kinases leads to dissociation of RB from E2F and subsequent progression through $S$ phase. Interaction with $\mathrm{E} 2 \mathrm{~F}$ occurs through a common structural feature of the $\mathrm{RB}$ family called the "pocket" region, and mutations in this region are often tumorigenic, suggesting that the inability to control E2F properly leads to increased proliferation.

Interactions of the $\mathrm{RB}$ and $\mathrm{E} 2 \mathrm{~F}$ family members are 
also cell-cycle dependent (see Slansky and Farnham 1996 and reviews within). RB interacts with E2F1-3 in the $G_{1}$ phase. The interaction of E2F-4 with p107 occurs in $G_{1}$ and $S$ phase in association with cyclins and CDKs. To add complexity, we and others have demonstrated a direct and functional interaction of cyclin A and CDK-2 with E2F-1 in the absence of RB family members. These observations suggest that there are multiple means of targeting CDK to E2Fs for cell cycle control (Dynlacht et al. 1994; Krek et al. 1994; Xu et al. 1994). In both quiescent and differentiated cells, we and others have also demonstrated that p130 is associated with E2F-4, and likely E2F-5 (Cobrinik et al. 1993; Shin et al. 1995; Moberg et al. 1996; Smith et al. 1996). Thus, there is considerable combinatorial complexity in the interactions of the RB and E2F families in dictating cell cycle transitions

Although the involvement of the RB family in $G_{1} / S$ control is well established, several diverse studies also suggested a critical role in terminal differentiation. Viral oncoproteins such as E1A, SV40 large T, and Polyoma Large $T$ can bind to the RB family members, and their expression prevents terminal differentiation. The ability of these viral oncoproteins to interfere with differentiation is dependent on the LXCXE sequence motif that is also required for their interaction with the RB family pocket region (Webster et al. 1988; Caruso et al. 1993; Maione et al. 1994).

Gene ablation studies have revealed some unique functions for RB, p107, and p130, but have also underscored the redundancy of their function (Clarke et al. 1992; Jacks et al. 1992; Lee et al. 1992, 1994, 1996; Cobrinik et al. 1996). The targeted disruption of the RB gene in mice leads to embryonic lethality, but not until day 13 , implicating its role in cellular differentiation and the development of specific phenotypes in specific tissues. Similarly, a double p107/p130 knockout exhibits neonatal lethality with defects in limb development, but suggests that intact RB gene can substitute for p107 and p130 in many developmental functions. Single p107 or p130 knockouts have no apparent phenotype, underscoring the extensive functional redundancy in the RB family.

Specificity of RB, pl30, and p107 could also be achieved through the use of different downstream cellular targets. In cell differentiation, the expression patterns of $\mathrm{RB}, \mathrm{p} 130$, and p107 suggest differential regulatory functions. RB and p130 expression is increased with differentiation; p107 levels decline (Maione et al. 1994; Schneider et al. 1994; this study). The E2F family represents the only example of selective downstream targets for RB, p107, and $\mathrm{p} 130$, and this specificity has provided insights into their differential role in cell cycle transitions. Whereas numerous cellular RB family binding proteins have been described, their role in differentiation and cell cycle control remains largely obscure with few notable exceptions (e.g., D-type cyclins, BRG-1/Swi2, E2Fs) (Dowdy et al. 1993; Ewen et al. 1993; Dunaief et al. 1994).

In this paper we describe the isolation of HBP1 as a new transcription factor target with selectivity for RB and p130. HBP1 was isolated originally in a different context and the previous work demonstrated that HBPl had homology to the sequence-specific high mobility group (HMG) class of transcription factors (Lesage et al. 1994). This transcription factor family includes LEFl and SRY, which have emerged as architectural proteins for specifying transcriptional enhancer function in normal development and differentiation (for review, see Grosschedl 1995). In this paper we provide evidence for several properties of HBP1 that suggest an intriguing and unique role as a transcriptional repressor that may regulate cell cycle arrest during cell differentiation.

\section{Results}

HBP1 is a new RB family target in differentiated cells

Critical features of terminal differentiation include irreversible cell cycle exit and the expression of differentiation-specific genes to specify tissue type. We have focused on the general cell cycle regulation associated with terminal differentiation. The $\mathrm{C} 2$ muscle cell line represents an excellent model because of the efficiency of terminal differentiation in culture. Our previous work has demonstrated that one target of differentiation signals is the E2F transcription factor and its interaction with p130 coincided with transcriptional repression (Shin et al. 1995).

To identify other targets of p130 in terminal differentiation, a two-hybrid screen was initiated with a cDNA library from fully differentiated C2 muscle cells. Of 26 positive cDNAs with varying specificities for $\mathrm{p} 130$, two independent isolates encoded the mouse homolog of a previously cloned rat protein, HBPl with $92 \%$ amino acid identity. No further attempt was made to isolate a full-length mouse HBP1 cDNA. HBP1 is a putative member of the sequence-specific class of HMG transcription factors and was isolated previously as a rat cDNA whose expression could complement a potassium channel defect in yeast but had no motifs characteristic of a membrane protein ion channel (Lesage et al. 1994). It was also demonstrated that HBP1 mRNA is up-regulated following terminal differentiation of both muscle cells and fat cells, suggesting that this transcription factor may be a general regulator of differentiation. Thus, HBP1 was a unique sequence-specific HMG transcription factor with a link to the RB family members and with differentiation-regulated expression.

Inspection of the amino acid sequence of HBP1 revealed both an LXCXE and an IXCXE motif, providing a molecular basis for the p130 interaction. LXCXE, and recently IXCXE, is a signature motif in viral and cellular proteins for interaction through the RB family pocket domains (Defeo-Jones et al. 1991; Dowdy et al. 1993; Ewen et al. 1993; Wang et al. 1993; Dunaief et al. 1994; Maione et al. 1994; Buyse et al. 1995; Singh et al. 1995). By yeast two-hybrid assay, the pocket region of p130 was essential for interaction with HBP1 (Fig. 1A). Similarly, mutation of the LXCXE motif in HBP1 abolished inter- 


\section{TEST STRAIN}

$$
\begin{aligned}
& 4 . \\
& 5 . \\
& 6 . \\
& 7 . \\
& 8 .
\end{aligned}
$$

1.

2.

3.

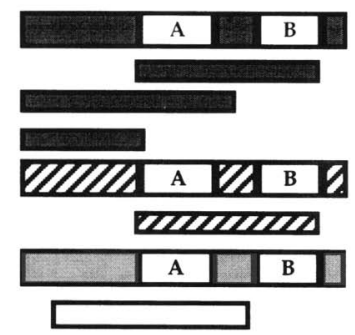

RB FAMILY CONSTRUCTS

full-length p130

p130-pocket only

p130-D-pocket B

p130-D-pocket A+B

Full length RB

RB-pocket only

ull-Length p107

DP-1
Figure 1. HBP1 and RB family interaction requires the LXCXE and pocket motifs. $(A)$ $\mathrm{HBP}$ l interacts with the pocket region of $\mathrm{RB}$ family members. Using the yeast two-hybrid assay (see Materials and Methods), the interaction of HBP1 with RB, p130, and p107 was scored. DP1 was used as a negative control. The amino-terminal region of murine HBPl (amino acids 1-133; clone 91) was fused to the activation domain and the test interactors were fused to the Gal4 DNAbinding region. A positive interaction resulted in the expression of the dual Gal4dependent reporters for $\beta$-gal and his3. The details for construction of p130 deletion mutants can be found on our web site. $(B)$ LXCXE of HBP1 is required for interaction with $\mathrm{p} 130$. The interaction of the aminoterminal portion of rat HBP1 (amino acids $1-120 ; B \|$ and the equivalent point mutation (Cys-37 to Gly; HBP37G; F) with p130 were scored by yeast two-hybrid assay. The criteria for interaction was growth in the absence of histidine. The IXCXE motif was not scored, because of toxicity of expression in yeast. The positive control pairs are SNF1/ SNF4 $(C) ; \mathrm{RB} / \mathrm{E} 1 \mathrm{~A}(D)$ and p130/E1A $(A)$. The negative control-pl30/SNF4 $(E)$ is the background for the assay. action with p130 (Fig. 1B). GST capture assays verified both results (data not shown). Together, these data support the notion that both the LXCXE motif of HBPl and the pocket motif of p130 were required for the interaction.

HBP1 interacts specifically with $R B$ and $p 130$, but not with p107 in mammalian cells

A significant requirement is the demonstration of a specific interaction of HBP1 with RB, p130, and/or p107 in mammalian cells. To delineate the interactions, cells were cotransfected with expression vectors for HAHBP1 and either p107, RB, or pl30. The interactions were subsequently analyzed by an immunoprecipitation-Western assay. As shown in Figure 2A, HBP1 interacted with RB and p130 (lanes 1 and 4), but not p107 (lane 3). As a positive control, each RB family member exhibited efficient interaction with E1A, indicating that the pocket regions of p130, RB, and p107 were intact (Fig. 2A, lanes 5-7).

Previous studies have demonstrated that RB levels rise in the underphosphorylated form with differentiation, but p107 levels fall (Maione et al. 1994; Schneider et al. 1994). As shown below in Figure 4A, p130 levels also rise with an accumulation of a more rapidly migrating species, suggesting that p130 and RB exhibited similar expression patterns upon differentiation. By analogy with $\mathrm{RB}$, the presence of a more rapidly migrating p130 species is also consistent with accumulation of the underphosphorylated form, but this remains to be confirmed.
As shown previously (Lesage et al. 1994) and in Figure 4B, HBP1 itself was also up-regulated about sixfold in the early stages of differentiation. Thus, the coordinate regulation of $\mathrm{HBP} 1, \mathrm{RB}$, and $\mathrm{p} 130$ support a role in terminal differentiation.

As in yeast and GST capture assays, the interactions in mammalian cells depended upon the LXCXE and IXCXE motifs. $\mathrm{A}^{35} \mathrm{~S}$-coimmunoprecipitation assay was used to detect interactions of full-length HBP1 and p130. The extent of interaction was expressed as percent bound to pl30 over total HBPl (Fig. 2B; lanes 1,2, and Fig. 2C; lanes 1-3), normalizing for differing expression levels of the mutant HA-HBP1. As shown in Figure 2B, the wildtype HBPl interacted specifically with p $130(37 \%$ of the total HBP1), consistent with the data in Figure 2A. In contrast, a control HMG protein (LEF-1, which contains no LXCXE motifs), gave no interaction (Fig. 2B, lane 4). Upon mutation of either LXCXE or IXCXE motifs, differing levels of p130 interaction remained $[\mathrm{pmIXC} 150 \%$ of total); Fig. 2C, lane 4; or pmLXC (7\% of total); Fig. 2C, lane 5]. However, mutation of both LXCXE and IXCXE completely abolished the interaction with p130 $\mid<1 \%$ of total; Fig. 2C, lane 6). Thus, the HBP1 interaction with the pocket of pl30 and $\mathrm{RB}$ required at least one of the two LXCXE and IXCXE motifs.

\section{HBP1 encodes a transcriptional repressor of the N-MYC promoter}

Previous work (Lesage 1994) placed HBP1 in the class of sequence-specific HMG proteins because of extensive 
A
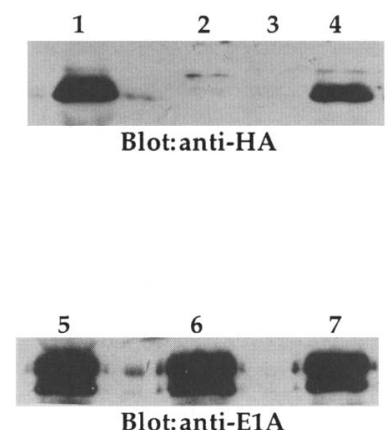

lane

1 anti-p130

2 anti-p107

3 control

4 anti-RB

Figure 2. In vivo interaction of p130 and HBP1 depends on LXCXE motifs. (A) HBPl interacts specifically with $\mathrm{RB}$ and $\mathrm{p} 130$, but not p107 in vivo. The in vivo interactions were scored by an immunoprecipitationWestern assay of extracts from $\mathrm{C} 33 \mathrm{~A}$ cell that were cotransfected with HA-HBP1 and p130, p107, or RB expression vectors. The cell extract was immunoprecipitated with anti-p130 (C-20 Santa Cruz; lane 1), antip107 (mixture SD6, 9,15-gift of Ed Harlow and Nick Dyson; lane 2) or anti-RB (N-9; gift of Bill Kaelin; lane 4), respectively. The other half was immunoprecipitated with a control antibody (preimmune sera for antiRB-gift of Bill Kaelin; lane 3). All immunoprecipita-

tions were resolved on a $7.5 \%$ SDS gel and then blotted with anti-HA (12CA5) to visualize HA-HBP1 ( $66 \mathrm{~K})$. As a positive control for the integrity of the pocket proteins, a parallel transfection was performed with adenovirus ElA. The immunoprecipitations proceeded as above, except that anti-E1 A (M73) was used to visualize the E1A in the p130, p107, and RB IPs (lanes 5-7). The E1A proteins migrate at $\sim 45 \mathrm{~K}$. $(B)$ In vivo interaction of pl30 with HBP1. Cells were cotransfected with expression vectors for p130 and either HA-HBP1 (lanes 1,3) or HA-LEF-1 (lanes 2,4; gift of Dr. Rudy Grosschedi). The indicated antibodies were used in a co-immunoprecipitation analysis that was performed as described in Materials and methods. Anti- $\beta$-Gal and rabbit antimouse antibodies were used as negative controls for the first and second immunoprecipitation, respectively. One-third of the extract was used to determine total protein expression levels by double anti-HA IP (HA-HBP1, lane 1; HA-LEF-1, lane 2). Positions of the HA-tagged proteins were indicated by arrows [HA-HBP1 ( -66K); HA-LEF-1 ( -50K). The remaining two-thirds were used for scoring interaction in a double immunoprecipitation with anti-p130 followed by anti-HA (lanes 3 and 4). The signal was quantitated by PhosphorImager analysis. The percentage of HA-tagged HBPl proteins that interacted with p130 in this assay was calculated as a ratio of bound to total. No interaction was observed between p130 and HA-LEF-1 (cf. lanes 2 and $4,<1 \%$ recovery), whereas $37 \%$ of the total HA-HBPl protein was recovered as bound to p130 lanes 1 and 3). (C) In vivo interactions between p130 and HBP1 mutants. Expression vectors encoding mutant HBP1 proteins (pmLXC, pm IXC, and pm L/I XCXE) were cotransfected with expression vector for pl30 into C33A cells. The double immunoprecipitation analysis proceeded as described in Fig. 2B. One-third of each input extract was analyzed for total expression by a double anti-HA IP (lanes 1-3), and the positions of HA-tagged proteins are indicated by arrow (pmIXC, lanes 1,4; pmLXC, lanes 2,5; pmL/IXCXE, lanes 3,6). The remaining two-thirds of the extract were analyzed for pl30 interaction by an anti-p130-immunoprecipitation followed by anti-HA immunoprecipitation. (lanes 4-6). The percentage of HA-tagged HBP1 mutant that interacted with p130 in this assay was determined by PhosphorImager and was normalized for differing expression by expressing a ratio of bound to total. The normalized values for lanes $4-6$ constituted $50 \%$ for pm IXC, $7 \%$ for pmLXC and $<1 \%$ for pmLXC/IXC.

homology with other HMG-box DNA-binding regions. This transcription factor class functions in an architectural role in the assembly of multifactor transcriptional complexes, insuring appropriate enhancer specificity (Carlsson et al. 1993; Giese et al. 1995; for review, see Grosschedl 1995). The best-studied members of this class are LEF-1 and SRY, which are transcriptional activators that are critical for murine development and differentiation (Gubbay et al. 1990; Genderen et al. 1994; Zhou et al. 1995).

HBP1 DNA sites exist in the N-MYC promoter Insight into the DNA-binding site of HBP1 came serendipi- tously. Repeated efforts to express HBPl from cytomegalovirus (CMV)-based expression vectors were unsuccessful. We decided to examine whether HBP1 might be binding to the CMV promoter and limiting its own expression. Using a recombinant HBPl with its HMG box fused to glutathione $S$-transferase (GST) we footprinted the CMV promoter and found three sites of interaction (TCAATGGG at -194 to $-187 ;-137$ to $-144 ;-134$ to $-127)$. We used the footprinting data as a query against the database to identify target genes. A perfect match was found in the promoter region of the N-MYC gene from rat (-484 to -477 ; GenBank accession no. X63281). Targeted gene disruption studies have demonstrated that 
N-MYC is essential for mouse organogenesis, a process that depends upon timely terminal differentiation events (Charron et al. 1992; Stanton et al. 1992). The most intriguing features of N-MYC were the previous demonstration that $\mathrm{E} 2 \mathrm{~F}$ regulated the expression during the cell cycle and that N-MYC expression levels declined with differentiation (Hiebert et al. 1991; Stanton et al. 1992; Hara et al. 1993). The existence of both E2F and HBP1 sites in the N-MYC promoter suggested that signals from both factors could be integrated through this pivotal cell cycle-regulated promoter.

Using recombinant HBP1 in a DNase footprinting assay, we tested whether the rat N-MYC promoter was indeed a target of HBPl. As shown in Figure 3A (lanes $3-9 \mid$, the interaction with recombinant HBP1 resulted in distinct and clear footprints on the N-MYC promoter from -504 to -511 and from -484 to -477 . From the functional binding data on the N-MYC and CMV promoters, a limited consensus sequence $[(\mathrm{A} / \mathrm{T}] \mid \mathrm{C} /$ G)AATGGG)] could be derived that has similarity to the LEF-1 binding site that was used in a recent nuclear magnetic resonance (NMR) structure determination of the LEF-1 HMG box (Love et al. 1995). Similar sequence is also present in yet another, distal site in the rat $(-66)$ to $-654)$ and also in the human (-853 to -850 ; GenBank accession no. M63717) and mouse (-591 to $-598 ;-441$ to -448 ; GenBank accession no. M12731) N-MYC promoters. The distal site on the rat N-MYC promoter was deleted from this probe, but other probes verified that this also was an HBP-1 site (data not shown). Furthermore, HBP1 that was expressed in mammalian cells could also recognize the N-MYC promoter probe in a standard gel shift assay (data not shown). Together, these data establish that HBP-1 binds specifically to sites within the NMYC promoter.

HBP1 encodes a sequence-specific transcriptional repressor Early studies had provided evidence that transcriptional repression was a likely mechanism in regulating N-MYC expression and suggested that the identification of repressors might be important in understanding N-MYC regulation in response to differentiation cues (Smith et al. 1992). We hypothesized that HBP1 might function as a transcriptional repressor based on the kinetics of expression upon differentiation. As cells execute the terminal differentiation program, HBP1 mRNA levels rise (Lesage et al. 1994) and N-MYC mRNA levels fall (Hara et al. 1993). In Figure 4B (lanes $1-3$, we have verified the reciprocal regulation of $\mathrm{N}$ MYC and HBP1 RNA and have added that HBP1 RNA was significantly up-regulated in the early phase of $\mathrm{C} 2$ differentiation.

To test whether HBPl could function as a transcriptional repressor, C33A cells were transiently cotransfected with a rat N-MYC-CAT chloramphenicol acetyl transferase reporter (Fig. 5A) and $\mathrm{HBP} 1$ expression vectors. Because of difficulties with CMV expression, HBP1 was expressed from the EF- $1 \alpha$ promoter in the pEF-BOS expression system (Mizushima and Nagata 1990). All wild-type and mutant $\mathrm{HBP} 1$ proteins were tagged with

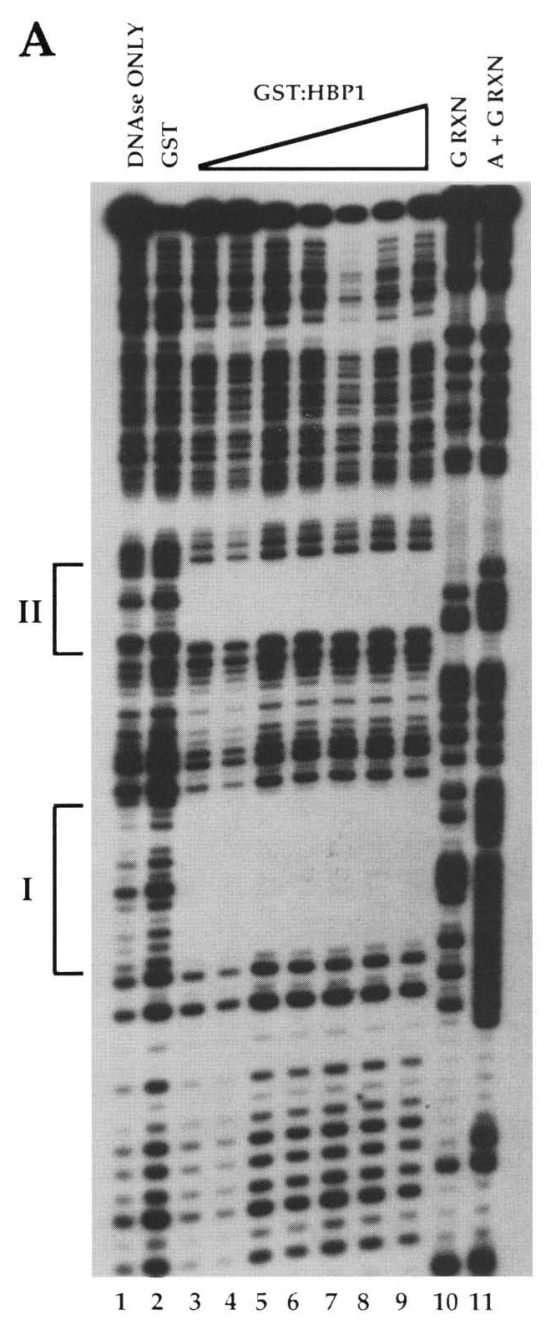

Figure 3. DNA-binding analysis of HBPl on the N-MYC promoter. DNAse footprint of recombinant HBP1: A 142-bp SphIAvaI fragment was excised from the rat N-MYC and encompassed the region -552 to -410 relative to the transcription initiation site. The rat N-MYC genomic construct was a generous gift of Dr. Kuchino (Sugiyama et al. 1991). DNase footprinting assays were performed as described previously (Shin et al. 1996) and in Materials and Methods. (Lane 1) The DNase ladder is shown; (lane 2), $3 \mu \mathrm{g}$ of purified GST were used as a control; (lanes 3-9) purified GST-HBP1 was used in a concentration range from $40 \mathrm{ng}$ to $3 \mu \mathrm{g}$. The GST-HBP1 contains the HMG region only. The position of the protected regions was defined by Maxam-Gilbert sequencing ladder in lanes 10 and 11. As shown in lanes 3-7, two clear areas of protection are apparent (I and II) and the boundaries are -504 to -511 and -484 to -477 , respectively.

the HA epitope to facilitate detection of transfected cells. The levels of HBP1 protein expression could be estimated only by immunofluorescence with anti-HA antisera; direct Western blots were not possible because of the presence of an HA-reactive background band that comigrated precisely at the molecular weight of HBP1.

As shown in Figure 5B, expression of HBP1 led to a 13-fold repression of the N-MYC promoter construct. 
A
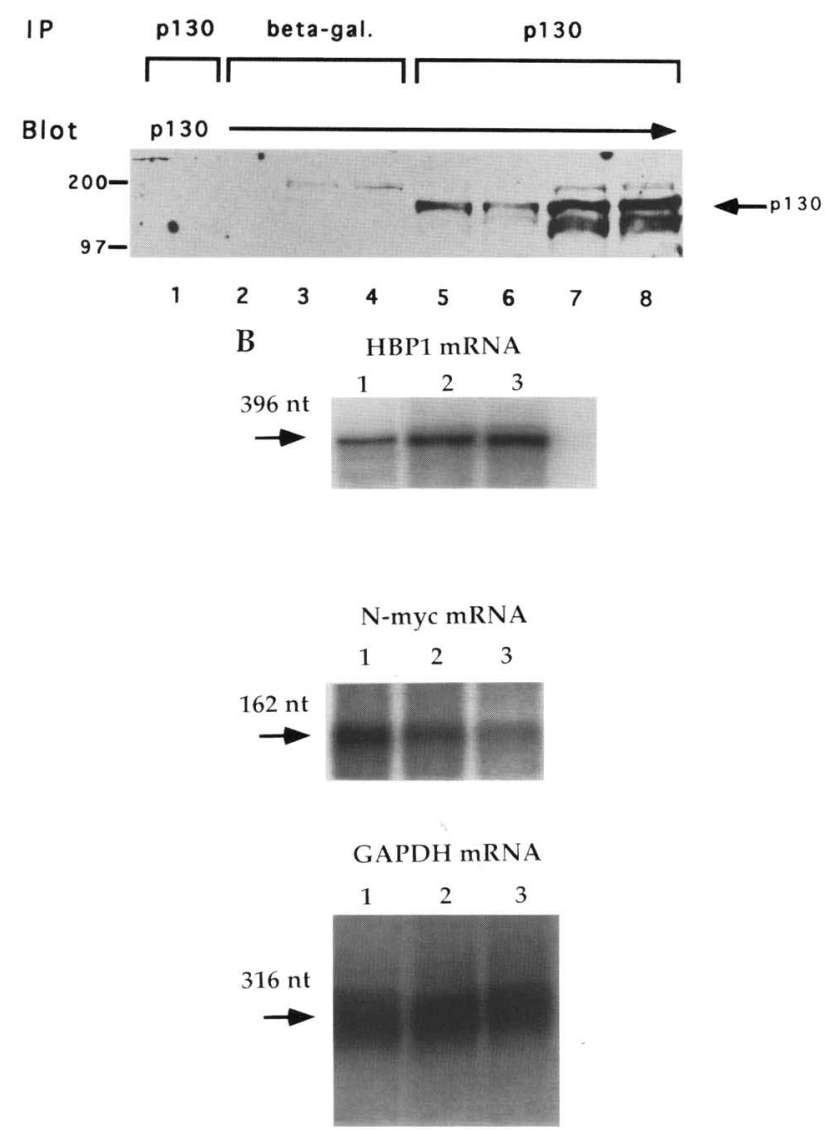

Figure 4. Expression pattern of N-MYC, HBP1, and p130 with C2 muscle cell differentiation. (A) Expression of the p130 protein is increased with differentiation. The expression of the pl30 protein was measured in extracts from undifferentiated (lanes 2,5,6) and fully differentiated C2 cells (lanes 3,4,7,8). Both nuclear (lanes 2,3,5,7) and cytoplasmic (lanes 4,6,8) extracts were prepared as described previously (Shin et al. 1995). All extracts were immunoprecipitated with either a control antibody (anti- $\beta$-Gal; 5-prime $\rightarrow 3$-prime; lanes 2-4) or with antip130 (Santa Cruz C-20; lanes 5-8). An additional pl30 immunoprecipitation was performed in the absence of extract to insure that the p130 antibody itself gave no signal (lane 1). All resulting immunoprecipitations were analyzed by SDS-PAGE and then blotted with anti-p130. The p130 signal is indicated. (B) Reciprocal regulation of N-MYC and HBP1 RNA with C2 differentiation. Undifferentiated $\mathrm{C} 2$ cells were subjected to differentiation media for 1 and 3 days. The latter represent full terminal differentiation. Total RNA $(150 \mu \mathrm{g})$ from either undifferentiated or differentiated $\mathrm{C} 2 \mathrm{C} 12$ cells were analyzed for $\mathrm{N}$ MYC (middle) and HBP1 (top) expression by ribonuclease protection assays (Tevosian et al. 1996). (Lanes 1-3) RNA from undifferentiated, 1 day of differentiation, and 3 days of differentiation, respectively. GAPDH mRNA was used as an invariant control (bottom). The specific protected fragments are indicated.

This result has been observed in 15 separate duplicate transfections with a range of 5- to 15 -fold repression; the level of repression was dependent on the level of HBP1 expression (data not shown). To demonstrate that the repression required DNA binding, the HMG box of HBP-1 was inactivated by triple point mutation (pmHMG). The amino acid substitutions were based on the positions of protein-DNA contacts in the NMR structure and mutagenesis of the homologous LEF-1 HMG domain (Giese et al. 1992; Love et al. 1995). The pm HMG mutant did not exhibit repression of the $\mathrm{N}$ MYC reporter. We also confirmed that pmHMG failed to bind DNA in an electrophoretic mobility shift assay and, like wild-type HBP1, was localized to both the nucleus and cytoplasm by immunofluorescence (data not shown). The repression by HBP1 on the N-MYC promoter was not limited to C33A cells, which was our test line, but was also observed at a similar level in C2 muscle and Caco2 intestinal lines (data not shown). As a positive control and because the N-MYC promoter contained E2F sites, expression of E2F-1 gave the published fourfold induction (e.g., Helin et al. 1992; Kaelin et al. 1992).

The repression of the N-MYC promoter was modulated by interaction with RB family members. HBP1 contains two RB family interaction motifs (LXCXE and IXCXE). As shown in Figure $5 B$, the mutation of either motif does not appreciably affect repression (cf. HBP-1 with pm LXC and pm IXC). However, mutation of both motifs reduced the repression activity (see pm L/IXC). Correspondingly, the physical interaction of HBP1 with p130 and RB was also abolished only upon mutation of both motifs, but binding did remain when one motif was intact (Fig. 2C). By immunofluorescence, the levels of expression of all mutants were similar in these experiments (data not shown). These data suggest that RBp130 interaction contributed to the repression properties of HBP1, but may not be the only factor dictating repression (see Discussion).

The gold-standard criteria for transcriptional repressors is the demonstration of sequence-specific repression at the promoter level and of an independent repression domain within the protein. In the first step, we tested whether HBP1 and its cognate DNA element could confer repression to a heterologous promoter. The HBP1 sites were placed upstream of the herpes simplex virusthymidine kinase (HSV-TK) promoter fused to the CAT gene (TK5HBPCAT). As a control, AP-1 sites, which do not bind HBPl (data not shown), were placed in the same TK CAT reporter (TK-AP-1-CAT). As shown in Figure $5 \mathrm{C}$, the expression of HBP1 led to efficient repression of this heterologous HBP1 reporter. In contrast, there was only modest inhibition of the control AP-1 reporter. Several other control promoters (e.g., B-Myb) were not affected by HBP1 expression in our test lines /data not shown). Thus, transcriptional repression by HBP1 required direct sequence-specific DNA binding and was not a consequence of nonspecific promoter interference. This experiment also demonstrated that HBPl repression did not have a strict requirement for appropriate promoter context, illustrating a major mechanistic distinction from the transcriptional activator LEF-1 (for review, see Grosschedl 1995). 
A
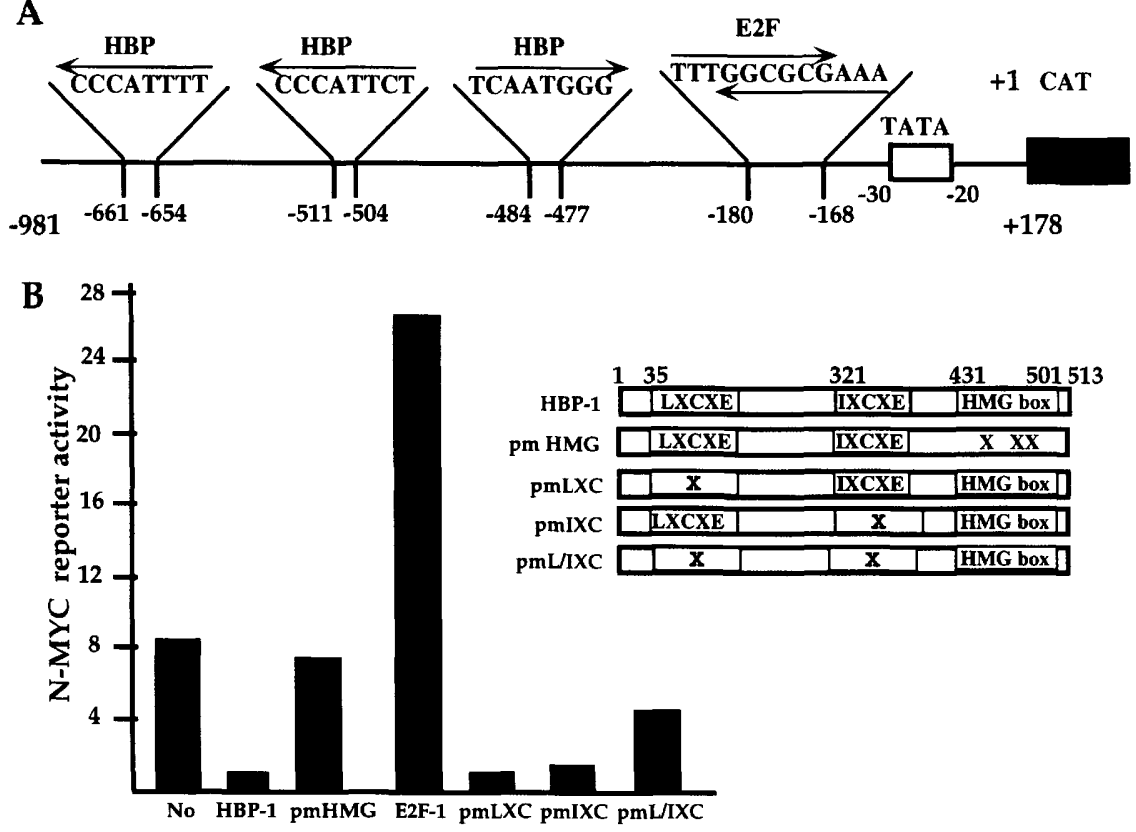

C

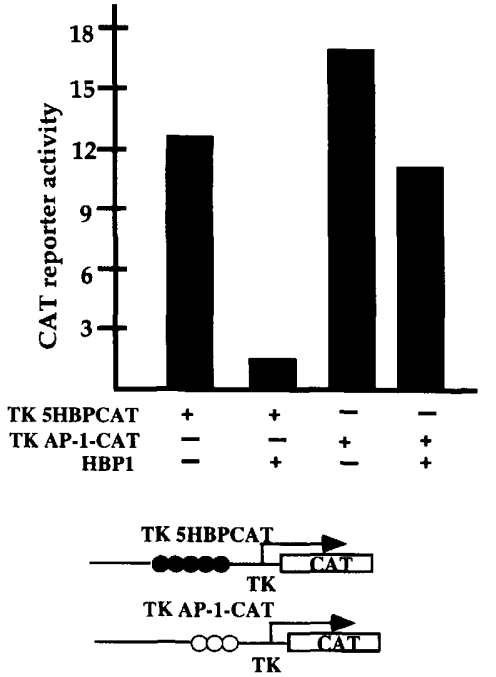

D

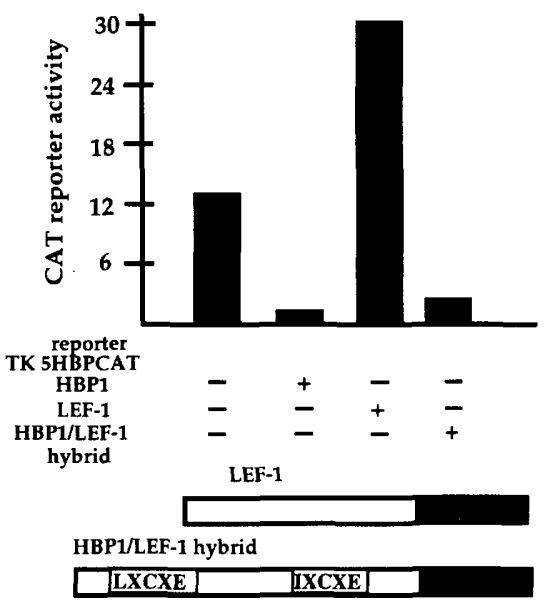

Figure 5. HBPl encodes a sequence-specific transcriptional repressor of N-MYC. (A) Schematic of the rat N-MYC promoter. The pUC-N-MYC-CAT reporter construct encompasses -981 to +178 of the rat N-MYC promoter relative to the transcriptional start site. The E2F and HBP1 sites are shown and represent only two types of transcription factors in this complex promoter. (B) HBP1-mediated N-MYC repression depends on DNA binding and RB-interaction motifs. The transcriptional activity was determined by transient transfection assay using $3 \mu \mathrm{g}$ of the indicated N-MYC reporter and pEF-BOS derived HBP1, CMV-E2F-1 (Xu et al. 1994), or pEF-BOS-based vectors encoding mutant HBP1 proteins in the DNA-binding $1 \mathrm{pm}$ HMG) or RB-interacting motifs: LXCXE (pmLXC), IXCXE (pmIXC), or both (pmL) IXC). RSV- $\beta$-gal was used as an internal transfection control. C33A cells were the test line, the quantitation of CAT protein and $\beta$-gal activity utilized the linear range of all assays and represents duplicate transfections that varied by $<10 \%$. The transcriptional output was expressed as a normalized ratio of CAT protein to $\beta$-gal activity units. All mutants are HA-tagged, and immunofluorescence demonstrated nuclear localization and equivalent protein expression (data not shown). As described in the Results, direct Western blots were not possible because of the presence of an HA-reactive cellular band at the molecular weight of HBP1. A representative experiment is shown. The positions of the relevant functional motifs in the HBP1 protein are indicated. $(C)$ Specific HBP1 binding is necessary for transcriptional repression. The schematics of the HBP1 TK and control TK CAT reporters are shown. C33A cells were transfected with $3 \mu \mathrm{g}$ of an indicated TK reporter con-
circles represent the HBPl sites from the struct in the presence or absence of $10 \mu \mathrm{g}$ of HBP1 expression vector. The filled and open circles represent the HBP1 sites from the N-MYC promoter and AP1 sites from the metallotheinin promoter, respectively (see Materials and Methods). CAT activity was normalized for transfection efficiency according to $\beta$-gal activity, as described in $B$. A representative experiment is shown. All experiments were repeated in duplicates at least three times and showed $<10 \%$ deviation of CAT activity between experiments. $(D)$ A region of HBPl can confer repression to a heterologous HMG box. To determine whether HBP1 could confer repression to a heterologous HMG box, a hybrid protein of HBPl with the LEF-1 HMG box was constructed as described in Materials and Methods. C33A cells were transfected with $3 \mu \mathrm{g}$ of the TK 5HBP CAT reporter plasmid and $10 \mu \mathrm{g}$ of the EF-BOS-based expression vectors. A representative experiment is shown. All experiments were repeated in duplicate at least three times and showed $<10 \%$ deviation of normalized CAT activity among experiments.

Two other diverse observations suggested the existence of an independent repression domain and that DNA binding alone was not sufficient for repression. First, expression of the HMG box of HBP1 was not sufficient to confer repression (data not shown). Second, LEF-1 expression does not confer repression to the NMYC reporter or to the synthetic HBPl promoter (TK5HBPCAT) (data not shown; Fig. 5D), although LEF-1 could bind the HBP1 DNA element when expressed in cell extracts or as purified, recombinant protein (data not shown). The expression of LEF-1 supported a modest (2.5-fold) activation of TK5HBPCAT (Fig. 5D, column 3 vs. 1), although well below the level of published experiments for LEF-1-specific activation (Giese et al. 1995). In contrast, HBPl gave efficient (10-fold) repression (Fig. 5D, column 2 vs. 1 ). In this experiment, LEF-1 and HBP1 are both HA tagged and by immunofluorescence, LEF-1 is expressed at approximately twofold higher level. 
A second criteria for a transcriptional repressor is the demonstration of an independent repression domain. Because of the modular nature of transcriptional factor domains, definitive demonstration of a repression domain would be the ability to confer repression to a heterologous DNA-binding domain. Because LEF-1 could bind but not repress through the HBPl sites, our strategy was to convert LEF- 1 into a repressor of N-MYC by creating an HBP1-LEF-1 chimera protein utilizing the LEF-1 HMG box. As shown in Figure 5D, the amino-terminal 395 amino acids of HBP1 could confer efficient repression when fused to the HMG box of LEF-1 (column 4). The HBP1 HMG box at amino acids 431-501 was not present in this chimera. In the amino-terminal region of HBP-1, there are no apparent motifs that correspond to known repression regions (for review, see Hanna-Rose and Hansen 1996). Together, these experiments provide strong evidence that HBP1 can function as a transcriptional repressor, which requires both sequence-specific DNA binding and an independent repression domain.

HBP1 and E2F co-regulate the N-MYC promoter Numerous studies have indicated that E2F can control transcription through the cell cycle and the E2F sites are a prominent feature of N-MYC promoter activation (e.g., Mudryj et al. 1990). Our results suggest that HBP-1 can repress transcription of N-MYC when cells exit the cell cycle and initiate the terminal differentiation program. Based on opposite transcriptional function, HBP-1 function should oppose E2F-dependent activation. Because the N-MYC promoter has both E2F and HBPl sites, this hypothesis was tested by determining whether increasing amounts of HBP-1 could overcome an E2F-dependent activation of N-MYC in a transfection assay and vice versa. As shown in Figure 6, increasing $\mathrm{HBPl}$ relative to E2F-1 led to a repression of N-MYC transcription (columns 4,5) and nullification of the E2F-1-dependent activation (column 3). By Western blot, E2F-1 levels were not reduced in response to increasing HBP1, suggesting that HBPI exerted a dominant effect on the N-MYC promoter rather than through inhibition of E2F-1 expression (data not shown). This titration of HBP1 and E2F responses may mimic the cellular situation when cells exit the cell cycle and initiate terminal differentiation, that is, the ratio of $\mathrm{HBP} 1$ to E2F-1 increases. To mimic conditions in cycling cells, the reciprocal titration was performed. E2F-1 could efficiently overcome the repression by HBP-1 (columns 6,7). In both cases, expression of HBP-1 alone or E2F-1 alone gave the expected transcriptional repression and activation, respectively (Fig. 6, columns 2,81. These data favor a model in which the relative ratio of HBP-1 to E2F-1 may determine the level of $\mathrm{N}-\mathrm{MYC}$ promoter activity. In cycling cells, E2F- 1 is high relative to HBP-1, favoring activation of N-MYC expression. In quiescent and differentiated cells, HBP-1 is high relative to E2F-1, favoring repression of N-MYC.

\section{Expression of HBP1 leads to cell cycle arrest}

The up-regulation of HBP1 expression in the early phase

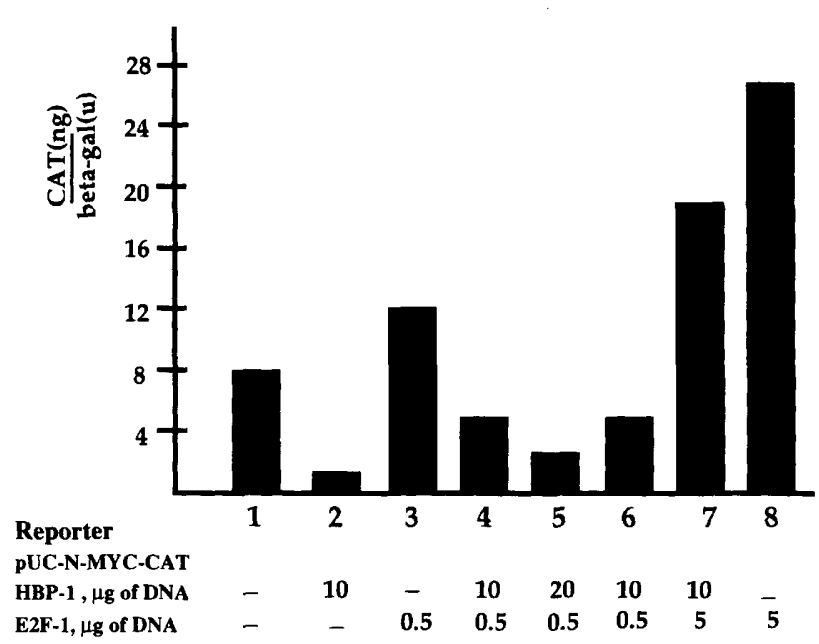

Figure 6. E2F-1 and HBP1 dictate opposite transcriptional regulation of the N-MYC promoter. Transfection experiments were performed as described in Materials and Methods with the indicated pEFBOS-HBP1 and CMV-E2F-1 expression vectors. The amount of HBP1 DNA used was optimized for detection by immunofluorescence; HBP1 is significantly more weakly expressed than E2F-1 (data not shown). The basal promoter activity of the N-MYC reporter is shown in column 1. Activation by E2F-1 is shown in columns 3 and 8 and repression by HBP1 of the N-MYC promoter is shown in column 2. The signals in response to increasing $\mathrm{HBPl}$ expression and constant E2F-1 is shown in columns 4 and 5 . The signals in response to increasing E2F-1 expression with constant HBP1 are shown in columns 6 and 7.

of differentiation and the functional repression of the $\mathrm{N}-\mathrm{MYC}$ promoter predict a role in the initiation and maintenance of cell cycle arrest. We tested this hypothesis by scoring $\mathrm{S}$ phase in $\mathrm{C} 2$ cells that were transiently transfected with HBP1. Bromodeoxyuridine (BrdU) incorporation was used as a measure of $S$ phase and double immunofluorescence was used in the analysis. The immunofluorescent detection analysis also demonstrated that transfected HA-HBP1 was localized in both the nucleus and cytoplasm. All HA-HBPl mutants that were constructed in this paper exhibited the identical localization (data not shown).

As shown in Figure 7, expression of HBP1 led to a fourfold reduction in the number of $S$-phase cells with an average of $5.4 \%$. $\beta$-gal, control-transfected C2 cells gave an average of $24 \%$ S-phase cells. By contrast, E2F-1, a known activator of $S$ phase, gave $58 \%$ cells in $S$ phase, which was consistent with the published results (Johnson et al. 1993). The cell cycle phenotype of HBP1 expression was dependent on the DNA-binding domain, as a DNA-binding defective mutant (pmHMG) failed to elicit cell cycle arrest and gave $22 \%$ BrdU-positive cells, which was consistent with the level in the control-transfected cell population. The HMG mutant serves as an ideal control for the phenotype of the wild-type HBP1. Because the pmHMG mutant also failed to induce $\mathrm{N}$ MYC repression (Fig. 5B), this suggested that an intact and functional HBP1 is required for both repression and 


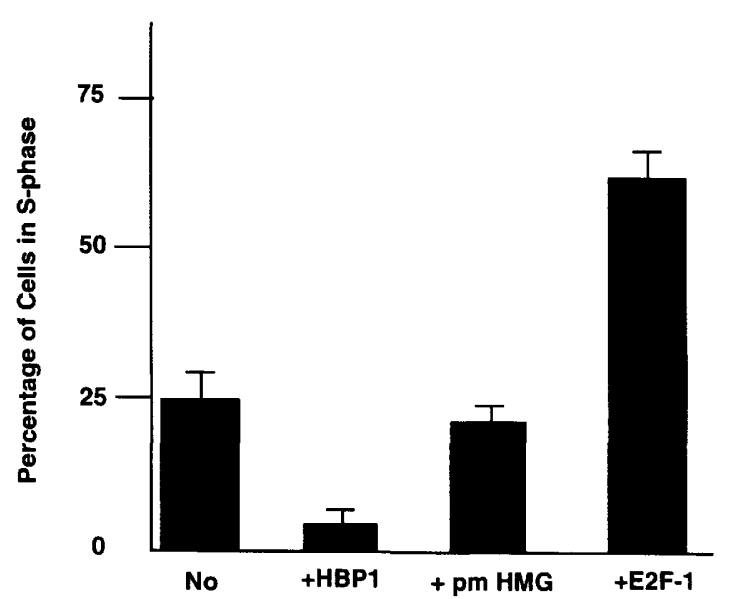

Figure 7. Expression of HBP1 leads to cell cycle arrest. The cell cycle phenotype of wild-type and pm HMG-HBP1 expression was scored by BrdU incorporation assay and immunofluorescence (see Materials and Methods). C2 cells were transfected with RSV $\beta$-gal alone or in conjunction with HA-HBP1. The immunofluorescent detection was performed as described in Materials and Methods. We used a 1-hr pulse with BrdU to capture the percentage of cells in S phase (Shin et al. 1996). Transfected cells were detected by $\beta$-gal immunofluorescence. The cotransfection efficiency for $\mathrm{HBPl}$ and $\beta$-gal expression was $72 \pm 4 \%$ and was determined by scoring the percentage of $\beta$-galpositive cells that were also HA positive. Next, the percentage of BrdU-positive and $\beta$-gal-positive transfected cells was quantitated in the presence and absence of HA-HBP1. Direct quantitation of HA- and BrdU-positive cells was not possible because both antibodies are of murine origin and simultaneous single cell, immunofluorescent detection cannot be performed. All data were expressed as a percentage of transfected or $\beta$-gal-positive cells and represents a compilation of three independent experiments. The control cells were mock-transfected with vectors expressing $\beta$-gal only and no HA-HBP1. In the control experiment (lane 1), the percentage of $\beta$-gal-positive cells that were also BrdU-positive was $24 \pm 4 \%$ ( $n=264 \beta$-gal-positive cells). As a positive control, the expression of E2F-1 (lane 4) led to $57.4 \pm 5 \%$ BrdU-positive cells; ( $n=272 \beta$-gal-positive cells). In the presence of HA-HBPl (lane 2), the percentage of BrdU-positive cells was reduced to $5.4 \pm 2 \%$; ( $n=494 \beta$-gal-positive cells). In the presence of pmHMG (lane 3), the percentage of BrdU-positive cells was $22.4 \pm 2 \%$ ( $n=194 \beta$-gal-positive cells).

the cell cycle phenotypes. It should also be noted that the cell cycle arrest manifested by HBP1 expression occurred under optimal growth condition, suggesting that HBP1 had a dominant cell cycle inhibitory effect and overrode existing proliferation signals.

\section{Discussion}

In this paper, we describe HBP1 as a new target of RB and p130 with unusual properties in cell differentiation. Like the E2Fs, HBP1 interactions can distinguish the homologous pocket regions of RB and $\mathrm{pl} 30$ from $\mathrm{p} 107$. The selectivity for p130 and RB is consistent with other work in which RB and pl 30 function is linked to differentiated cells and p107 function is linked to cycling cells $\mid \mathrm{Co}-$ brinik et al. 1993; Shin et al. 1995; Moberg et al. 1996;
Smith et al. 1996). HBP1 is a sequence-specific HMG box transcription repressor. Although the mechanisms of transcriptional activation by HMG box factors such as LEF1, Sox-2, and SRY have been delineated elegantly by Grosschedl and others, the identification and mechanisms of transcriptional repressors have not been defined. Transcriptional repression mediated by HBP1 required both sequence-specific DNA binding and unique repression domain. Intriguingly, HBP1 sites are contained within the promoter for N-MYC, which also contains E2F sites. These two transcription factors provide opposite regulatory and cell cycle signals, which may be integrated within the N-MYC promoter. Lastly, the expression of HBP1 in growing cells led to cell cycle arrest. As with the N-MYC promoter repression, this effect was dependent upon an intact DNA-binding domain in HBP1. The cell cycle arrest induced by HBP1 expression is particularly striking because optimal growth signals were present, suggesting that HBP1 expression could fully override the existing proliferation pathways to induce cell cycle arrest.

What is the postulated role of HBP1 in terminal differentiation? We suggest that HBP1 functions in the initiation and the maintenance of irreversible cell cycle arrest-a general feature of numerous tissues. We and others have demonstrated that quiescence is necessary but not sufficient for full differentiation. Subsequent tissuespecific steps are required to specify the differentiated cell type (Peterson et al. 1990; Shin et al. 1995; for review, see Buckingham 1994; Olson and Klein 1994). Although HBPl expression led to consistent cell cycle arrest, full differentiation of the muscle cells was not observed in our experiments, suggesting that HBP1 may function in the more general cell cycle regulatory step.

A model that summarizes results in this paper and other published work in the context of cell cycle control and N-MYC repression is depicted in Figure 8. The reciprocal expression patterns of HBP1 and N-MYC suggest that HBP1 could function as a repressor of N-MYC upon cellular differentiation. The up-regulation of HBP-1 in the early stages of differentiation suggests a role in initiation and establishment of cell cycle arrest. In differentiated cells, we postulate that HBP, p130, and E2Fs may contribute to maintenance of cell cycle arrest through a global repression of important cell cycle promoters like N-MYC. Our previous work has correlated transcriptional repression with the appearance of a p130 E2F 4/5 complex in terminal differentiation (Shin et al. 1995 ) and this complex may provide a given level of regulation. The presence of multiple HBP-1 sites in the NMYC promoter and the observed increase of HBP1 with differentiation suggest that occupancy of all sites may induce efficient and complete repression. The cell cycle arrest phenotype and repression of the N-MYC promoter by HBP1 are consistent with published studies of N-MYC expression patterns and the importance of its transcriptional repression in differentiation (Smith et al. 1992; Hara et al. 1993). The evolutionary conservation of HBP-1 sites in all N-MYC promoters also suggests a fundamental and important role. 
Figure 8. Summary and working model of HBP1 function. Our working model is that HBP1 transcriptional repression is required for cell cycle arrest. A possible promoter target is N-MYC, in which expression is down-regulated with cell differentiation when HBP1 expression is elevated (Fig. 4B; Lesage et al. 1994). (Top) The cell cycle data from Fig. 7 and published observations. The observation that E2F-1 expression induces $S$ phase has been published (Johnson et al. 1993; Qin et al. 1994) and was verified as shown in Fig. 7. (Bottom) A schematic summary of N-MYC promoter regulation by HBP1 and E2F family members. We postulate that HBP1 can repress the N-MYC promoter in differentiated cells, but E2F-1 can activate NMYC in cycling cells. The activation of N-MYC promoter by E2F-1 was demonstrated in Fig. 6, and we have extrapolated published data to include E2F-2 and E2F-3 as activators of E2F sites in the cell cycle (Wu et al. 1995; Lukas et al. 1996). In Figs. 5-7, we have demonstrated that HBP1 can function as a transcriptional repressor of N-MYC promoter. A caveat is that no effects of HBP1 expression on the endogenous N-MYC gene have been demonstrated directly; however, there is a correlation of HBP1 up-regulation and N-MYC down-regulation with muscle differentiation (Fig. 4B). Consistent with the data in Figs. 2 and 5B, the p130 and RB proteins function as potential regulators of HBPl. This specificity is consistent with the observation that the levels of both RB and pl30 rose in differentiated cells (Maione et al. 1994; Fig. 4), whereas p107 levels declined sharply upon differentiation (Schneider et al. 1994). The E2F4/5 complex with p130 has been defined by our laboratory and others (Cobrinik et al. 1993; Shin et al. 1995; Moberg et al. 1996) and we have correlated the appearance of this complex with transcriptional repression. Whether HBP1, p130, and E2F4/5 collaborate to elicit repression remains to be determined.

In cycling cells, previous studies have demonstrated that N-MYC expression is high in proliferating cells, probably as a result of activation of the E2F sites (Hiebert et al. 1991; Hara et al. 1993). In the current study, we utilized E2F-1, which is the best-characterized E2F family member, but recent work indicates that E2F1-3 may share redundant function in terms of S-phase gene regulation (e.g., Wu et al. 1995; Lukas et al. 1996). The elegant E2F-1 knockout work has suggested that E2F-1 may have an additional and surprising role in tumor suppression, but also suggested that upon ablation of E2F-1, the other E2Fs may contribute to the cell cycle function (Field et al. 1996; Yamasaki et al. 1996). Regardless of the precise E2F family member involved, our experimental observations illustrate the importance of both E2F and HBP sites in the cell cycle and differentiation control of the N-MYC promoter.

It is important to emphasize that Figure 8 represents only a summary and working model that will require further experiments. Although we have demonstrated that the N-MYC promoter can be repressed by HBP1 in transient assays, we can only demonstrate a correlation in terminal differentiation in which HBPl levels rise when N-MYC levels fall. Because of the apparent cell cycle arrest phenotype, we speculate that HBP1 may be a global regulator of cell cycle-dependent promoters, but firm evidence requires the identification of other promoters and of endogenous genes.

Our studies also indicate that transcriptional repression by HBP1 may be multifactorial, and RB-pl30 interaction may be just one contributing factor. In the HBP1 studies, the inability to bind RB and p130 does compromise, but does not completely eliminate transcriptional repression. This transcriptional regulation on HBP1 differs from E2F-1 in which RB binding appears to block its transcriptional activation function by direct binding and through recruitment of a repression function (e.g., Flemington et al. 1993; Helin and Harlow 1993; Sellers et al. 1995). It is possible that RB-p130 may augment intrinsic HBP1 repression by supplying its own repression region, which has been demonstrated for RB in promoter tethering studies (e.g., Sellers et al. 1995). No repression domain has yet been shown for $\mathrm{p} 130$. Recent studies have delineated the HBP1 repression region to a $\sim 100$-aminoacid domain containing the IXCXE motif; this region has no known homology to previously published repression motifs (S.G. Tevosian, H.H. Shih, and A.S. Yee, in prep.). An alternative possibility is that $\mathrm{HBP} 1, \mathrm{RB}$, and $\mathrm{p} 130$ 
may have a dual role both in cell cycle control and in cell survival upon differentiation. These dual functions were demonstrated for the p21 CDK inhibitor (Wang and Walsh 1996).

The dominant growth control mechanisms of HBP1 may be important features of organogenesis. A paradox of organogenesis has been the inability of organs to proliferate despite the presence of optimal growth conditions provided by the blood supply. Interestingly, the cell cycle arrest induced by HBP1 occurred under optimal growth conditions suggests that HBP1 expression can completely override the normal proliferation signals of a growth factor-rich environment. The presence of dominant growth inhibitors such as HBPl may provide one explanation for the block in proliferation and the maintenance of the cell cycle arrest phenotype of differentiated cells and organs in an optimal growth environment. Future studies of HBP1 function and regulation should provide new insights into mechanisms of transcriptional repression and cell differentiation.

\section{Materials and methods}

A more detailed description of all constructs and protocols can be accessed as a link to the Yee laboratory web site (http:// biba.med.tufts.edu/Biochemistry/Faculty/yee.htmll.

\section{Constructs for yeast expression}

p130 and mutant derivatives The p130 "bait" for the yeast two-hybrid system was based on the pAS2 yeast expression vector (Harper et al. 1993) and were derivatives of pBS-(S)F-130 (Li et al. 1993). Several p130 deletions were also constructed in pAS2 as GAL4 fusions and are outlined in Figure 1. pAS2-RB encodes the pocket domain and is a derivative of pGEX-2TKRb+ vector (Kaelin et al. 1992)

HBP1 and mutant derivatives Clone 91 or mouse HBPl: pACT-Clone 91 was isolated by the two hybrid screen with p130 and contained the amino-terminal 133 amino acids of murine HBP1. This fragment shares $92 \%$ amino acid identity with the published rat homolog (Lesage et al. 1994) For simplicity, most constructs utilized the rat HBPl (referred to as HBPl.) Wild-type HBP1 and derivative mutants: pACT-HBP1 vector for the yeast expression of the fusion of a full-length rat HBP1 cDNA with the activation domain of GAL4. pmLXC: In pACT(N120)-HBP1(37G), a point mutation was introduced in the LXCXE domain at the position 109 of the wild-type rat HBP1, changing cysteine 37 to glycine.

\section{Bacterial expression constructs}

GST HBP1 (HMG only): The bacterial expression vector for the HMG domain of rat HBP1 was obtained by subcloning EcoRI fragment of the pACT-HBP1 containing the coding sequence for amino acids $394-513$ of HBP1 into the pGEX-1 expression vector (Pharmacia).

\section{Mammalian expression constructs}

Unless indicated, p130 and all HBP1 constructs utilized the pEF-BOS expression system (Mizushima and Nagata 1990). All experiments in mammalian cells utilized an HA-tagged full- length rat HBP1 in which there was $92 \%$ amino acid identity with our murine HBP1 isolate (clone 91) (Lesage et al. 1994). All derivative mutants of HA-HBP-1 were constructed by PCR mutagenesis, as described on http://biba.med.tufts.edu/biochemistry/faculty/yee.html. pmHMG: The triple point mutation in the HMG DNA-binding domain of HBP1 was generated by overlapping PCR. Point mutations were introduced at the positions 434,435 , and 437 changing lysine- 434 to glutamic acid (AAA to GAA), arginine- 435 to glutamic acid (AGA to GAA) and methionine-437 to threonine (ATG to ACG). The amino acids were selected based on alignment with the LEF-1 HMG box in which these residues form DNA-protein contacts (Love et al. 1995). pmLXC: Cys-109 of rat HBP1 LXCXE motif was converted to Gly. pmIXC: Cys-323 of rat HBP1 IXCXE motif was converted to Gly. pmLXC/IXCXE: Both Cys-109 and Cys-323 of the LXCXE and IXCXE motifs, respectively were converted to Gly. HBP1/LEF1 chimera: In the pEF-BOS HBP1/LEF-1 expression vector, the HMG domain of HBP1 was replaced with HMG domain of LEF-1(Giese et al. 1995).

\section{N-MYC reporter constructs}

N-MYC CAT reporter: As diagramed in Figure 5A, N-MYC CAT contained -981 to +178 sequences and encompasses the promoter and first exon of the rat N-MYC gene and was constructed from the rat genomic N-MYC gene (pNM5; Sugiyama et al. 1991). HBP1 TK CAT: The nucleotide sequence of the HBPSI oligonucleotides used to create a synthetic HBP site are as follows: $5^{\prime}$-agctTCCTTCAATGGGGA and $5^{\prime}$-agctTCCCCATTGAAGGA. pHBP5TK-CAT was constructed by inserting five copies of the annealed HBPSI oligonucleotides at the HindIII site of the TK-CAT (Jantzen et al. 1987; Weintraub et al. 1990). AP-1 TK CAT: AP-1 oligonucleotides represent an AP-1 binding site in the metallothionein promoter: $5^{\prime}$-agctTCAAGTGACTCAGCGA and 5'-agctTCGCTGAGTCACTTGA. pTK AP-1-CAT was constructed as described above, except that three copies of the annealed AP-1 oligonucleotides were inserted.

\section{Two-hybrid screening}

Specific p130-interacting proteins were isolated in a two-hybrid screen (Harper et al. 1993) and using a cDNA library constructed in $\lambda$ ACTII from fully differentiated $C 2$ muscle cells. A true positive was defined as a cDNA encoding a "prey" protein that was able to interact with the original bait (p130) but not with irrelevant proteins [e.g., SNF1 (gift of S. Elledge, Baylor College, Houston, TX) or RAL (gift of L. Feig, Tufts University, Boston, MA)].

\section{DNase I footprint analysis}

The DNase I footprint analysis were performed essentially as described previously (Shin et al. 1996). The probe contained sequences -552 to -410 of the rat N-MYC promoter.

\section{Ribonuclease protection assays}

Total RNA was isolated from undifferentiated and differentiated $\mathrm{C} 2 \mathrm{C} 12$ cells with TriPure Isolation Reagent (Boehringer Mannheim/ according to manufacturer specifications and treated with ribonuclease-free DNase to remove residual DNA. T2 RNase protection assays were performed essentially as described previously (Tevosian et al. 1996). The input probes were derived from the murine N-MYC (gift of S. Reddy, Tufts University, Boston, MA) or HBP-1 cDNAs or from pTRI-GAPDH- 
Mouse template (Ambion). The specific protected fragments are indicated.

\section{Cell culture, DNA transfections, and CAT assays}

$\mathrm{C} 33 \mathrm{~A}$ and $\mathrm{C} 2 \mathrm{C} 12$ cells were cultured and transfected as described previously (Shin et al. 1995). CAT activity in cell extracts was determined with a CAT ELISA kit (Boehringer Mannheim) according to manufacturer's specifications. All transfection data was normalized by $\beta$-galactosidase activity, which was quantitated by an ONPG assay using a linear standard curve. The normalized reporter activity was expressed as a ratio of ngCAT to unit $\beta$-gal.

\section{Immunoprecipitation-Western}

Extracts of transfected C33A cells were prepared as described on our web site. For RB family member interactions, the antibodies used were anti-p130 polyclonal antisera (Santa Cruz, $5 \mu \mathrm{g}$ ), antiRB polyclonal antisera (a generous gift from Dr. Bill Kaelin, 2 pl), and a mixture of anti-p107 monoclonal antibodies SD6, SD9, and SD15 (a generous gift from Dr. Nick Dyson and Dr. Ed Harlow; $33 \mu \mathrm{ll}$. Anti-hemagglutinin (HA) epitope monoclonal antibody 12CA5 was used to immunoprecipitate HA-tagged wild type or mutant $\mathrm{HBP}$ at 1:1 dilution. For immunoblots, $12 \mathrm{CA} 5$ was used with ECL detection.

\section{${ }^{35} S$-labeling and immunoprecipitation}

For double immunoprecipitation analysis, each p100 plate of C33A cells was transfected with the indicated plasmids and labeled with [ ${ }^{35}$ S]-methionine, cysteine. Express label (NEN) at $1 \mathrm{mCi} /$ plate in serum-free media [1× Hanks salt solution (GIBCO) equilibrated with sodium bicarbonate] for $4 \mathrm{hr}$. Extracts were prepared essentially as described (Ginsberg et al. 1994) with modifications. Immunoprecipitations utilized the antibodies described above. Signals were analyzed by PhosphorImager.

\section{BrdU incorporation assays and immunofluorescence}

The S-phase assays were performed on $\mathrm{C} 2 \mathrm{C} 12$ cells essentially as described previously (Johnson et al. 1993; Shin et al. 1996; our web site). $\beta$-gal was used as a marker of transfected cells. To insure efficient coexpression of $\beta$-gal and HA-HBPl, cells were analyzed by indirect double immunofluorescence with rabbit anti- $\beta$-gal and rhodamine-conjugated goat anti-rabbit IgG and with murine mAb $12 \mathrm{CA} 5$ and FITC-conjugated donkey antimouse IgG. For visualization of all nuclei in a field, the coverslips were stained with Hoechst dye (final concentration of 25 $\mu \mathrm{g} / \mathrm{ml}$ in DMEM-2\% CS) for $3 \mathrm{~min}$ at room temperature. All coverslips were examined using fluorescence microscopy with the appropriate filters.

\section{Acknowledgments}

We are grateful to numerous colleagues whose generosity made this study possible: Stephen Elledge (two-hybrid system), Michel Lazdunski (rat HBP1), Yoshiyuki Kuchino (rat N-MYC), Dona Chikaraishi (pUC-CAT), Rudolf Grosschedl (LEF-1, manuscript comments), Nick Dyson and Ed Harlow (p107 and SD6,9,15], Bill Kaelin and David Livingston [RB, E2F-1, anti-RB (N9)] Eva Lee (RB), Stuart Orkin (pEF-BOS), Peter Whyte (p130), Wen-Hwa Lee (E2F-1), and Joe Nevins (CMV E1A; critical comments). We especially thank all member laboratories of the Tufts Signal Transduction Supergroup Meeting and especially
Brent Cochran, Larry Feig, and Brian Schaffhausen for many helpful discussions. This work was supported by a grant to K.E.P. from the National Institutes of Health (NIH) (DK 50442) and in part with federal funds from the United States Department of Agriculture (USDA) Agricultural Research Service, under contract 53-3K06-01 to K.E.P. The contents of this publication do not necessarily reflect the views or policies of the USDA nor does mention of trade names, commercial products, or organizations imply endorsement by the U.S. government. This work was also supported by grants to A.S.Y. from the NIH (GM44634), a core grant from the Digestive Disease Center at New England Medical Center (NIDDK, P30 DK-34928), and a Junior Faculty Research Award from the American Cancer Society (JFRA-360). A.S.Y. is an Established Investigator of the American Heart Association. Because of space limitation, we apologize to many colleagues whose original papers could not be cited.

The publication costs of this article were defrayed in part by payment of page charges. This article must therefore be hereby marked "advertisement" in accordance with 18 USC section 1734 solely to indicate this fact.

\section{References}

Bagchi, S., R. Weinmann, and P. Raychaudhuri. 1991. The retinoblastoma protein copurifies with E2F-I, an E1A-regulated inhibitor of the transcription factor E2F. Cell 65: 1063-1072.

Buckingham, M. 1994. Molecular biology of muscle differentiation. Cell 78: 15-21.

Buyse, I., G. Shao, and S. Huang. 1995. The retinoblastoma protein binds to RIZ, a zincfinger protein that shares an epitope with the adenovirus E1A protein. Proc. Natl. Acad. Sci. 92: 4467-4471.

Carlsson, P., M.L. Waterman, and K.A. Jones. 1993. The hLEF/ TCK- $1 \alpha$ HMG protein contains a context-dependent transcriptional activation domain that induced the TCR $\alpha$ enhancer in T cells. Genes \& Dev. 7: 2418-2430.

Caruso, M., F. Martelli, A. Giordano, and A. Felsani. 1993. Regulation of MyoD gene transcription and protein function by the transforming domains of the adenovirus E1A oncoprotein. Oncogene 8: 267-278.

Charron, J., B.A. Malynn, P. Fisher, V. Stewart, L. Jeannotte, S. Goff, E.J. Robertson, and F. Alt. 1992. Embryonic lethality in mice homozygous for a targeted disruption of the N-myc gene. Genes \& Dev. 6: 2248-2257.

Chellapan, S., S. Hiebert, M. Mudryi, J. Horowitz, and J.R. Nevins. 1991. The E2F transcription factor is a cellular target for the RB protein. Cell 65: 1053-1061.

Chittenden, T., D. Livingston, and W.G. Kaelin. 1991. The $\mathrm{T} / \mathrm{E} 1 \mathrm{~A}$ binding domain of the retinoblastoma product can interact selectively with a sequence-specific DNA binding protein. Cell 65: 1073-1082.

Clarke, A.R., E.R. Maandag, M. van Roon, M. van der Lugt, M. van der Valk, M.L. Hooper, A. Berns, and H.T. Riele. 1992. Requirement for a functional $\mathrm{Rb}-1$ gene in murine development. Nature 359: 328-330.

Cobrinik, D., P. Whyte, D. Peeper, T. Jacks, and R. Weinberg. 1993. Cell cycle-specific association of E2F with the p130 ElA-binding protein. Genes \& Dev. 7: 2392-2404.

Cobrinik, D., M.H. Lee, G. Hannon, G. Mulligan, R.T. Bronson, N. Dyson, E. Harlow, D. Beach, R.A. Weinberg, and T. Jacks. 1996. Shared role of the pRB-related pl30 and p107 protein in limb development. Genes \& Dev. 10: 1633-1644.

Defeo-Jones, D., P. Huang, R. Jones, K. Haskell, G. Vuocolo, M. Hanobik, H. Huber, and A. Oliff. 1991. Cloning of cDNAs for 
cellular proteins that bind to the retinoblastoma gene product. Nature 352: 251-253.

Dowdy, S.F., P.W. Hinds, P. Louie, S.I. Reed, and R.A. Weinberg. 1993. Physical interaction of the retinoblastoma protein with D-type cyclins. Cell 73: 499-511.

Dunaief, J.L., B.E. Strober, S. Guha, P.A. Khavari, K. Alin, J. Luban, M. Begemann, G. Crabtree, and S. Goff. 1994. The retinoblastoma protein and BRG1 form a complex and cooperate to induce cell cycle arrest. Cell 79: 119-130.

Dynlacht, B., O. Flores, J.A. Lees, and E. Harlow. 1994. Differential regulation of E2F trans-activation by cyclin/cdk2 complexes. Genes \& Dev. 8: 1772-1786.

Ewen, M., H.K. Sluss, C.J. Sherr, H. Matsuhime, J. Kato, and D.M. Livingston. 1993. Functional interactions of retinoblastoma and D-type cyclins. Cell 73: 487-497.

Farnham, P.J. 1996. Transcriptional control of cell growth: The E2F family. Springer Verlag, New York, NY.

Field, S.J., F.Y. Tsai, F. Kuo, A.M. Zubiaga, W.G. Kaelin, D.M. Livingston, S.H. Orkin, and M.E. Greenberg. 1996. E2F-1 functions in mice to promote apoptosis and suppress proliferation. Cell 85: 549-561.

Flemington, E.K., S.H. Speck, and W.G. Kaelin. 1993. E2F-1 mediated transactivation is inhibited by complex formation with the retinoblastoma susceptibility gene product. Proc. Natl. Acad. Sci. 90: 6914-6918.

Genderen, C.V., R.M. Okamura, I. Farinas, R.G. Quo, T.G. Parslow, L. Bruhn, and R. Grosschedl. 1994. Development of several organs that require inductive epithelial-mesenchy$\mathrm{mal}$ interactions is impaired in LEF-1-deficient mice. Genes \& Dev. 8: 2691-2703.

Giese, K., J. Cox, and R. Grosschedl. 1992. The HMG domain of lymphoid enhancer factor 1 bends DNA and facilitates assembly of functional nucleoprotein structures. Cell 69: 185195.

Giese, K., C. Kingsley, J. Kirshner, and R. Grosschedl. 1995. Assembly and function of a TCR- $\alpha$ enhancer complex is dependent on LEF-1-induced DNA bending and multiple protein-protein interactions. Genes \& Dev. 9: 995-1008.

Ginsberg, D., G. Vairo, T. Chittenden, Z.H. Xiao, G. Xu, K.L. Wydner, J. DeCaprio, J. Lawrence, and D.M. Livingston. 1994. E2F-4, a new member of the E2F transcription factor family, interacts with p107. Genes \& Dev. 8: 2665-2679.

Grosschedl, R. 1995. Higher order nucleoprotein complexes in transcription: Analogies with site-specific recombination. Curr. Opin. Cell Biol. 7: 362-370.

Gubbay, J., J. Collignon, P. Koopman, B. Capel, A. Economou, A. Munsterberg, N. Vivian, P. Goodfellow, and R. Lovell-Badge. 1990. A gene mapping to the sex-determining region of the mouse y chromosome is a member of a novel family of embryonically expressed genes. Nature 346: 245-250.

Hanna-Rose, W. and U. Hansen. 1996. Active repression mechanisms of eukaryotic transcriptional repressors. Trends Genet. 12: 229-234.

Hara, E., S. Okamoto, S. Nakada, Y. Taya, S. Sekiya, and K. Oda. 1993. Protein phosphorylation required for the formation of E2F complexes regulates $\mathrm{N}$-myc transcription during differentiation of human embryonal carcinoma cells. Oncogene 8: $1023-1032$.

Harper, J.W., G. Adami, N. Wei, K. Keyomarski, and S. Elledge. 1993. The p21 CDK-interacting protein $\mathrm{Cipl}$ is a potent inhibitor of G1 cyclin-dependent kinases. Cell 75: 805-816.

Helin, K. and E. Harlow. 1993. The retinoblastoma protein as a transcriptional repressor. Trends Cell Biol. 3: 43-46.

Helin, K., J.A. Lees, M. Vidal, N. Dyson, E. Harlow, and A. Fattaey. 1992. A cDNA encoding a pRB-binding protein with properties of the transcription factor E2F. Cell 70: 337-350.
Hiebert, S.W., M. Blake, J. Azizkhan, and J.R. Nevins. 1991. Role of E2F transcription factor in E1A-mediated trans activation of cellular genes. T. Virol. 65: 3547-3391.

Huang, S., E. Shin, K.A. Sheppard, L. Chokoroverty, B. Shan, Y.W. Qian, E.Y. H.P. Lee, and A.S. Yee. 1992. The retinoblastoma protein region required for interaction with the E2F transcription factor includes the T/E1A binding and carboxy-terminal sequences. DNA Cell Biol. 11: 539-548.

Jacks, T., E.M. Fazeli, E. Schmitt, R.T. Bronson, M. A. Goodell, and R.A. Weinberg. 1992. Effects of an Rb mutation in mice. Nature 359: 295-300.

Jantzen, H.M., U. Strahle, B. Gloss, F. Stewart, W. Schmid, M. Boshart, R. Miksicek, and G. Schutz. 1987. Cooperativity of glucocorticoid response elements located far upstream of the tyrosine aminotransferase gene. Cell 49: 29-38.

Johnson, D.G., J.K. Schwarz, W.D. Cress, and J.R. Nevins. 1993. Expression of transcription factor E2F-1 induces quiescent cells to enter S phase. Nature 365: 349-352.

Kaelin, W.G., W. Krek, W.R. Sellers, J.A. DeCaprio, F. Ajchanbaum, C.S. Fuchs, T. Chittenden, Y. Li, P.J. Farnham, M.A. Blanar, D.M. Livingston, and E.K. Flemington. 1992. Expression cloning of a cDNA encoding a retinoblastoma-binding protein with E2F-like properties. Cell 70: 351-364.

Krek, W., M. Ewen, S. Shirodkar, Z. Arany, W. Kaelin, and D. Livingston. 1994. Negative regulation of the growth-promoting transcription factor E2F-1 by a stably bound cyclin Adependent protein kinase. Cell 78: 161-172.

Lee, E.H.Y.P., C.Y. Chang, N. Hu, Y.C.J. Wang, C.C. Lai, K. Herrup, W.H. Lee, and A. Bradley. 1992. Mice deficient for $\mathrm{Rb}$ are nonviable and show defects in neurogenesis and hematopoiesis. Nature 359: 288-294.

Lee, E.Y.-H.P., N. Hu, S.-S.F. Yuan, L. Cox, A. Bradley, W.-H. Lee, and K. Herrup. 1994. Dual roles of the retinoblastoma proteins in cell cycle regulation and neuron differentiation. Genes \& Dev. 8: 2008-2021.

Lee, M.H., B.O. Williams, G. Mulligan, S. Mukai, R.T. Bronson, N. Dyson, E. Harlow, and T. Jacks. 1996. Targeted disruption of p107: Functional overlap between p107 and Rb. Genes \& Dev. 10: 1621-1632.

Lesage, F., J.P. Hugnot, E.Z. Amri, P. Grimaldi, J. Barhanin, and M. Lazdunski. 1994. Expression cloning in the $\mathrm{K}^{+}$transportdefective yeast and regulation of $\mathrm{HBP1}$, a new putative HMG transcriptional regulator. Nucleic Acids Res. 22: 3685-3688.

Li, Y., C. Graham, S. Lacy, A. Duncan, and P. Whyte. 1993. The adenovirus E1A-associated $130 \mathrm{kD}$ protein is encoded by a member of the retinoblastoma gene family and physically interacts with cyclins A and E. Genes \& Dev. 7: 2366-2377.

Livingston, D.M., W.G. Kaelin, T. Chittenden, and X. Qin. 1993. Structural and functional contributions to the G1 blocking action of the retinoblastoma protein. Br. J. Cancer 68: $264-268$.

Love, J.J., X. Li, D.A. Case, K. Giese, R. Grosschedl, and P.E. Wright. 1995. Structural basis for DNA bending by the architectural transcription factor Lef -1. Nature 376: 791-795.

Lukas, J., B.O. Petersen, K. Holm, J. Bartek, and K. Helin. 1996. Deregulated expression of E2F family members induces Sphase entry and overcomes p16-INK4-mediated growth suppression. Mol. Cell. Biol. 16: 1047-1057.

Maione, R., G. Fimia, P. Holman, B. Schaffhausen, and P. Amati. 1994. Retinoblastoma antioncogene is involved in the inhibition of myogenesis by polyomavirus large $\mathrm{T}$ antigen. Cell Growth Differ. 5: 231-237.

Mizushima, S. and S. Nagata. 1990. pEF-BOS, a powerful mammalian expression vector. Nucleic Acids Res. 18: 5322.

Moberg, K., M.A. Starz, and J.A. Lees. 1996. E2F-4 switches from p130 to p107 and pRB in response to cell cycle re-entry. Mol. 
Cell. Biol. 16: 1436-1449.

Mudryi, M., S. Hiebert, and J.R. Nevins. 1990. A role for the adenovirus-inducible E2F transcription factor in a proliferation dependent signal transduction pathway. EMBO J. 9: 2179-2184.

Olson, E.N. and W.H. Klein. 1994. bHLH factors in muscle development: Dead lines and commitments, what to leave in and what to leave out. Genes \& Dev. 8: $1-8$.

Peterson, C., H. Gordon, Z. Hall, B. Paterson, and H. Blau. 1990 Negative control of the helix-loop-helix family of myogenic regulators in the NFB mutant. Cell 62: 493-502.

Qin, X.Q., D.M. Livingston, W.G. Kaelin, and P.D. Adams. 1994. Deregulated transcription factor E2F-1 expression leads to S-phase entry and p53-mediated apoptosis. Proc. Natl. Acad. Sci. 91: 10918-10922.

Riley, D.J., E.Y.-H.P. Lee, and W.-H. Lee. 1994. The retinoblastoma protein: More than a tumor suppressor. Annu. Rev. Cell Biol 10: 1-29.

Schneider, J.W., W. Gu, L. Zhu, V. Mahdavi, and B. Nadal-Ginard. 1994. Reversal of terminal differentiation mediated by p107 in Rb - / - muscle cells. Science 264: 1467-1470.

Sellers, W.R., J.W. Rodgers, and W.G.J. Kaelin. 1995. A potent transrepression domain in the retinoblastoma protein in duces a cell cycle arrest when bound to E2F sites. Proc. Natl. Acad. Sci. 92: 11544-11548.

Shin, E., A. Shin, C. Paulding, B. Schaffhausen, and A.S. Yee. 1995. Multiple changes in E2F transcription factor function occur upon muscle differentiation. Mol. Cell. Biol. 15: 22522262.

Shin, E., S.G. Tevosian, and A.S. Yee. 1996. The N-terminal region of E2F-1 is required for transcriptional activation of a new class of target promoter. I. Biol. Chem. 271: 1226112268.

Singh, P., J. Coe, and W. Hong. 1995. A role for the retinoblastoma protein in potentiating transcriptional activation by the glucocorticoid receptor. Nature 374: 562-565.

Slansky, J. and P.J. Farnham. 1996. Introduction to the E2F family: Protein structure and gene regulation. In Transcriptional control of cell growth: The E2F gene family (ed. P.J. Farnham), pp. 1-30. Springer-Verlag, New York, NY.

Smith, E.J., G. Leone, J. DeGregori, L. Jakoi, and J.R. Nevins. 1996. The accumulation of an E2F-p130 transcriptional repressor distinguishes a $\mathrm{G}_{0}$ cell state from a $\mathrm{G}_{1}$ cell state. Mol. Cell. Biol. 16: 6965-6976.

Smith, R.K., K. Zimmerman, G.D. Yancopoulos, A. Ma, and F.W. Alt. 1992. Transcriptional down-regulation of N-MYC expression during B-cell development. Mol. Cell. Biol. 12: $1578-1584$.

Stanton, B.R., A. Perkins, L. Tessarollo, D. Sassoon, and L. Parada. 1992. Loss of $\mathrm{N}$-myc function results in embryonic lethality and failure of the epithelial component of the embryo to develop. Genes \& Dev. 6: 2235-2247.

Sugiyama, A., Y. Miyagi, Y. Shirasawa, and T. Kuchino. 1991. Different usage of two polyadenylation signals in transcription of the N-Myc gene in rat tumor cells. Oncogene 11: $2027-2032$.

Tevosian, S., K.E. Paulson, R. Bronson, and A.S. Yee. 1996. Expression of the E2F-1/DP-1 transcription factor during murine development. Cell Growth Differ. 7: 43-52.

Wang, C.Y., B. Petryniak, C.B. Thompson, W.G. Kaelin, and J.M. Leiden. 1993. Regulation of the Ets-related transcription factor Elf- 1 by binding to the retinoblastoma protein. Science 260: $1330-1335$.

Wang, J. and K. Walsh. 1996. Resistance to apoptosis conferred by cdk inhibitors in myocyte differentiation. Science 273: 359-361.
Webster, K.A., G. Muscat, and L. Kedes. 1988. Adenovirus Ela products suppress myogenic differentiation and inhibit transcription from muscle-specifc promoters. Nature 332: 553557.

Weintraub, H., R. Davis, D. Lockshon, and A. Lassar. 1990. MyoD binds cooperatively to two sites in a target enhancer sequence: Occupancy of two sites is required for activation. Proc. Natl. Acad. Sci. 87: 5623-5627.

Wu, C.L., L. Zukerberg, C. Ngwu, E. Harlow, and J.A. Lees. 1995. In vivo association of E2F and DP family proteins. Mol. Cell. Biol. 15: 2536-2546.

Xu, M., K.A. Sheppard, C.Y. Peng, A.S. Yee, and H. PiwnicaWorms. 1994. Cyclin A/CDK2 binds directly to E2F-1 and inhibits the DNA-binding activity of E2F-1/DP-1 by phosphorylation. Mol. Cell. Biol. 14: 8420-8431.

Yamasaki, L., T. Jacks, R. Bronson, E. Golliot, E. Harlow, and N. Dyson. 1996. Tumor induction and tissue atrophy in mice lacking E2F-1. Cell 85: 537-548.

Zhou, P., C. Byrne, J. Jacobs, and E. Fuchs. 1995. Lymphoid enhancer factor 1 directs hair follicle patterning and epithelial cell fate. Genes \& Dev. 9: 570-583. 


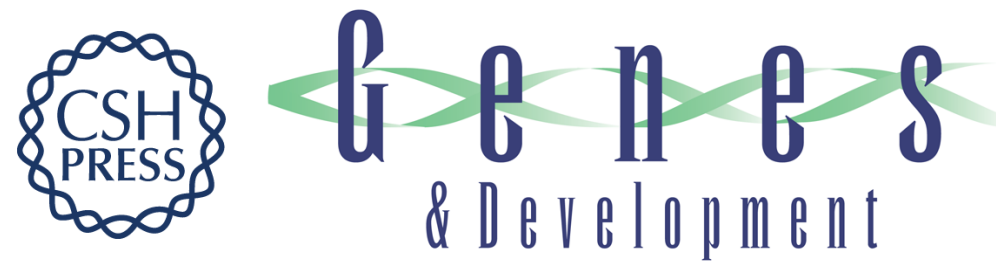

\section{HBP1: a HMG box transcriptional repressor that is targeted by the retinoblastoma family.}

S G Tevosian, H H Shih, K G Mendelson, et al.

Genes Dev. 1997, 11:

Access the most recent version at doi:10.1101/gad.11.3.383

References This article cites 70 articles, 31 of which can be accessed free at: http://genesdev.cshlp.org/content/11/3/383.full.html\#ref-list-1

License

Email Alerting

Service

Receive free email alerts when new articles cite this article - sign up in the box at the top right corner of the article or click here.

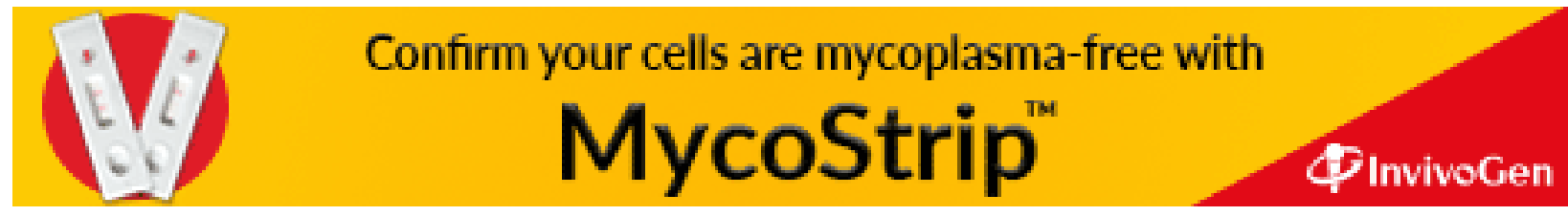

